\title{
Production of Neofusicoccum species conidia and their pathogenicity on wounded and non-wounded blueberry shoots
}

\author{
K.M.S. Tennakoon, H.J. Ridgway, M.V. Jaspers and E.E. Jones \\ Department of Pest-Management and Conservation, Faculty of Agriculture and Life Sciences, \\ Lincoln University, PO Box 85084, Lincoln 7647, New Zealand \\ Corresponding author: Eirian.Jones@lincoln.ac.nz
}

\begin{abstract}
Pycnidial and conidial production by isolates of the four main Neofusicoccum species associated with blueberry in New Zealand was investigated. Pycnidia developed after 8 days on mycelial-inoculated detached green shoots. Conidial ooze was observed after further incubation for $12 \mathrm{~h}$ under high relative humidity at $25^{\circ} \mathrm{C}$. Numbers of oozing pycnidia and conidial numbers were generally low, but were significantly affected by isolate and species. Neofusicoccum ribis and N. parvum produced slightly more pycnidia and conidia compared with N. luteum and $N$. australe. Inoculation of non-wounded and wounded attached green shoots with either $N$. ribis or $N$. australe conidia showed that, 14 days after inoculation, lesions developed in wounded shoots only, with $N$. ribis $(58.8 \mathrm{~mm})$ producing longer lesions than $N$. australe $(29.8 \mathrm{~mm})$. Neofusicoccum ribis and $N$. australe were re-isolated beyond the lesion, with pathogen progression being significantly greater for wounded $(47.1 \mathrm{~mm})$ compared with nonwounded shoots $(30.4 \mathrm{~mm})$.
\end{abstract}

Keywords Botryosphaeriaceae, Vaccinium ashei, cirrhi, wounding, inoculum.

\section{INTRODUCTION}

Botryosphaeriaceae species are important pathogens of blueberry throughout the world. The main species reported to be associated with blueberry decline worldwide are Fusicoccum aesculi, Neofusicoccum arbuti, N. australe, N. parvum, N. ribis and Lasiodiplodia theobromae (Xu et al. 2015; Espinoza et al. 2009; Wright \& Harmon 2010; Creswell \& Milholland 1988). In New Zealand, recent sampling of blueberry plant material from both nurseries and fields resulted in the isolation of $N$. australe, $N$. luteum, N.parvum, and N. ribis, with N. australe being the most prevalent species (Tennakoon
2017). Further, when inoculated onto wounded blueberry shoots, all were shown to cause lesions, with $N$. ribis reported to be the most pathogenic species based on lesion length (Tennakoon 2017). However, although these species have been reported as pathogens of blueberry, the majority of studies investigating their pathogenicity have used mycelial plugs, which do not represent the natural inoculum sources in nurseries and farms. Many Botryosphaeriaceae species, however, do not readily sporulate in culture, which led Amponsah et al. (2008) to develop a method for production of conidia on grapevine green 
shoots. The potential of using this method for producing conidia of the main Neofusicoccum species associated with blueberry decline in New Zealand on blueberry shoot tissue, however, has not been determined. In addition, the relative production of conidia by these species, and the variation between isolates within a species in their ability to produce conidia is unknown.

Botryosphaeriaceae pathogens are generally considered to infect through wounds (Tennakoon et al. 2015). However, Milholland (1971) reported the infection of both wounded and non-wounded blueberry shoots using F. aesculi conidia. Whether conidia of the species prevalent in New Zealand are able to infect non-wounded blueberry stems has not been reported.

The overall aim of the study was to determine the variability in conidial production between different isolates of the main Neofusicoccum species associated with blueberry decline on detached blueberry stem tissue. This will provide information as to the suitability of this method for conidial production of these species for use in subsequent pathogenicity experiments. Additionally, the ability of conidial inoculum of $N$. australe and $N$. ribis to infect wounded and non-wounded blueberry shoots was evaluated.

\section{MATERIALS AND METHODS}

\section{Origin and maintenance of fungal isolates}

Four isolates each of N. australe (LUPP1281, 1301, 1321, 1364), N. luteum (LUPP 1308, 1320, 1332, 1357), N. ribis (LUPP1300, 1340, 1348, 1365) and N. parvum (LUPP1249, 1288, 1328, 1363) were used. These isolates were originally isolated from blueberry in a New Zealand nationwide survey (Tennakoon 2017) and obtained from the Lincoln University Plant Microbiology culture collection. Fungal isolates were stored as mycelial plugs on PDA in $20 \%$ glycerol at $-80^{\circ} \mathrm{C}$ and routinely cultured on potato dextrose agar (PDA; DIFCO $^{\mathrm{TM}}$, New Jersey, USA) at $25^{\circ} \mathrm{C}$.

\section{Induction of sporulation on detached green blueberry shoots}

Detached soft green blueberry ('Dolce blue') shoots $(\sim 5 \mathrm{~mm}$ in diameter, $20-25 \mathrm{~cm}$ cut from the tip) were inserted into a Universal bottle filled with water and the top of the bottle wrapped with Parafilm (Pechiney Plastic Packaging Co., Chicago, IL). The shoots were surface sterilised by swabbing with $70 \%$ ethanol, superficially wounded with a sterile scalpel $(\sim 1-2 \mathrm{~mm}$ deep and $4-6 \mathrm{~mm}$ in diameter) and inoculated with a 3-mm diameter mycelial plug cut from the edge of a 3-day-old PDA culture of one of the isolates or sterile agar for the controls. The ten replicate shoots per treatment were placed in an enclosed transparent humid chamber, in a randomised block design and incubated at room temperature $\left(20-25^{\circ} \mathrm{C}\right)$ with $12 \mathrm{~h}$ light and $12 \mathrm{~h}$ dark, with frequent misting for the first three days. After 8 days incubation, when pycnidia had developed, the central $15 \mathrm{~mm}$ of the lesions were excised to standardise the length of lesioned tissue being investigated. These sections were then surface sterilised in $1 \%$ sodium hypochlorite for $1 \mathrm{~min}$, followed by $30 \mathrm{~s}$ in $70 \%$ alcohol and rinsed twice in sterile distilled water before air drying for $6 \mathrm{~h}$ under a sterile air flow in a laminar-flow hood as described by Amponsah et al. (2008). These were then placed on sterilised moist paper towels in separate Petri dishes to minimise cross contamination, and incubated for $12 \mathrm{~h}$ at $25^{\circ} \mathrm{C}$ to allow pycnidia to ooze cirrhi of conidia. The Petri dishes were arranged in a randomised block design in the incubator. The numbers of oozing pycnidia and conidia from each section were counted as described by Amponsah et al. (2008).

\section{Pathogenicity on wounded and non-wounded blueberry shoots}

One conidial suspension $\left(10^{6} / \mathrm{mL}\right)$ was made from a mixture of three the $N$. australe isolates [LUPP1301, 1321, 1364,]. A second conidial suspension with the same concentration was made from the three N. ribis isolates [LUPP1340, 1348, 1365]. Thirty six three-year-old plants of blueberry cultivar 'Dolce Blue' were used. Soft green shoots were wounded as described previously or non-wounded. Each inoculation site was marked with a permanent marker pen and wrapped with Parafilm to form a lip. The sites were immediately inoculated with $50 \mu \mathrm{L}$ 
drops of a mixed isolate conidial suspension. Control plants were inoculated with sterile water. Plants were arranged in a completely randomised design in a shadehouse. Six plants were used for each treatment combination and two shoots were inoculated on each plant. Plants were observed after 1, 2, 3, 4, 6, 7, 10 and 14 days for lesion development. At 14 days after inoculation, the lesion lengths were measured with a digital caliper. The length of tissue colonised by the pathogens was assessed 14 days after inoculation. The central $11 \mathrm{~cm}$ section of the shoot $(5 \mathrm{~cm}$ above to $5 \mathrm{~cm}$ below the $1 \mathrm{~cm}$ inoculation point) was removed and surface sterilised by dipping in $70 \%$ ethanol for $30 \mathrm{~s}$ followed by air drying in a laminar flow hood for $10 \mathrm{~min}$. The shoot piece was then cut into $1 \mathrm{~cm}$ sections, the outer bark removed from the underlying wood, and the tissues plated separately onto PDA, as described by Tennakoon et al. (2015). The plates were incubated at $25^{\circ} \mathrm{C}$ under $12 \mathrm{~h}$ light and $12 \mathrm{~h}$ dark conditions for 3-5 days, and N. australe and $N$. ribis isolates growing from the tissue pieces identified by colony appearance.

\section{Statistical analysis}

Data of pycnidial and conidial numbers, lesion lengths and pathogen isolation distances were analysed by general analysis of variance (ANOVA) using Genstat 16 to determine treatment effects. Comparisons between means of individual treatments used Fisher's protected LSDs at $\mathrm{P} \leq 0.05$. The correlation between the numbers of oozing pycnidia and conidia was analysed by simple linear regression using Genstat 16.

\section{RESULTS}

\section{Induction of sporulation on detached green blueberry shoots}

Oozing pycnidia were observed on the lesions for all isolates after $12 \mathrm{~h}$ incubation. Numbers of oozing pycnidia were significantly affected by isolate $(\mathrm{P}<0.001$; Table 1$)$. The highest number of pycnidia were produced by $N$. parvum LUPP1363, which produced significantly more pycnidia than all other isolates except $N$. ribis LUPP1340 and N. luteum LUPP1357. When the isolate data were combined to determine the species effect, a second analysis showed that there was a significant effect of species $(\mathrm{P}=0.004$; $L S D=45.12$ ). The mean number of oozing pycnidia was significantly higher $(\mathrm{P}<0.05)$ for $N$. ribis (196 pycnidia/15 mm shoot) and N.parvum (165 pycnidia/15 mm shoot) compared with $N$. luteum (130 pycnidia/15 mm shoot) and $N$. australe (118 pycnidia/15 mm shoot). Numbers of conidia produced were significantly affected by isolate ( $\mathrm{P}=0.004$; Table 1$)$. The highest number of conidia were produced by $N$. parvum LUPP1288, which was significantly higher than all other isolates except $N$. parvum LUPP1363 and $N$. ribis LUPP1348 and LUPP1365. The effect of species was also significant $(\mathrm{P}<0.003$; $\mathrm{LSD}=0.58)$, with $N$. ribis $\left(1.8 \times 10^{5} / \mathrm{mL}\right)$ and N. parvum, $\left(1.9 \times 10^{5} / \mathrm{mL}\right)$ being significantly higher compared with $N$. australe $\left(1.2 \times 10^{5} / \mathrm{mL}\right)$ and $N$. luteum $\left(0.9 \times 10^{5} / \mathrm{mL}\right)$.

There was a significant positive linear correlation $\left(\mathrm{R}^{2}=0.241 ; \mathrm{P}=0.05\right)$ between the number of oozing pycnidia and the number of conidia (Figure 1). However, N. parvum isolate LUPP1288 and $N$. ribis isolate LUPP1348 appeared to produce more conidia than predicted based on the number of pycnidia.

\section{Pathogenicity on wounded and non-wounded blueberry shoots}

Brown to black lesions developed on the inoculated wounded soft green shoots within three to four days. The lesion lengths were significantly $(\mathrm{P}<0.001)$ affected by species, with mean lesion lengths being significantly greater for $N$. ribis $(58.8 \mathrm{~mm})$ than for $N$. australe $(29.8 \mathrm{~mm})$. In non-wounded tissues, $N$. australe caused no lesions but sites inoculated with $N$. ribis had some brown dots in some soft green shoots, which did not develop into lesions. In the uninoculated controls, no lesions developed apart from some minor discolouration at the wound sites.

Incidence of isolated colonies characteristic of the inoculated Neofusicoccum species from inoculated wounded and non-wounded shoots was $100 \%$, with no Botryosphariaceae isolates 
Table 1 Mean number of oozing pycnidia (number $/ 15 \mathrm{~mm}$ shoot) and conidia $\left(\mathrm{x} 10^{5} / \mathrm{mL}\right)$ produced by four isolates of four Neofusicoccum species on detached green blueberry shoots (cultivar 'Dolce Blue').

\begin{tabular}{llll}
\hline Species & Isolate & Oozing pycnidia & $\begin{array}{l}\text { Number Conidia } \\
\left(\mathrm{x} 10^{5} / \mathrm{mL}\right)\end{array}$ \\
\hline Neofusicoccum australe & LUPP1281 & $51 \mathrm{a}^{1}$ & $1.1 \mathrm{ab}$ \\
N. australe & LUPP1301 & $161 \mathrm{bcde}$ & $1.6 \mathrm{abcd}$ \\
N. australe & LUPP1321 & $129 \mathrm{abcd}$ & $1.3 \mathrm{abc}$ \\
$N$. australe & LUPP1364 & $133 \mathrm{abcd}$ & $0.9 \mathrm{ab}$ \\
Neofusicoccum luteum & LUPP1308 & $96 \mathrm{ab}$ & $0.7 \mathrm{a}$ \\
$N$. luteum & LUPP1320 & $82 \mathrm{ab}$ & $0.7 \mathrm{a}$ \\
$N$. luteum & LUPP1332 & $135 \mathrm{abcd}$ & $1.0 \mathrm{ab}$ \\
$N$. luteum & LUPP1357 & $208 \mathrm{cdef}$ & $1.3 \mathrm{abc}$ \\
Neofusicoccum parvum & LUPP1249 & $123 \mathrm{abc}$ & $1.3 \mathrm{abc}$ \\
$N$. parvum & LUPP1288 & $138 \mathrm{abcde}$ & $2.9 \mathrm{e}$ \\
$N$. parvum & LUPP1328 & $127 \mathrm{abcd}$ & $1.3 \mathrm{abc}$ \\
$N$. parvum & LUPP1363 & $272 \mathrm{f}$ & $2.0 \mathrm{bcde}$ \\
Neofusicoccum ribis & LUPP1300 & $170 \mathrm{bcde}$ & $1.0 \mathrm{ab}$ \\
$N$. ribis & LUPP1340 & $215 \mathrm{def}$ & $1.5 \mathrm{abcd}$ \\
$N$ ribis & LUPP1348 & $171 \mathrm{bcde}$ & $2.6 \mathrm{de}$ \\
$N$ ribis & LUPP1365 & $228 \mathrm{ef}$ & $2.3 \mathrm{cde}$ \\
\hline LSD & & 90.2 & 1.16 \\
\hline
\end{tabular}

${ }^{1}$ Values within columns followed by the same letter are not significantly different according to Fisher's protected LSD at $\mathrm{P}=0.05$.

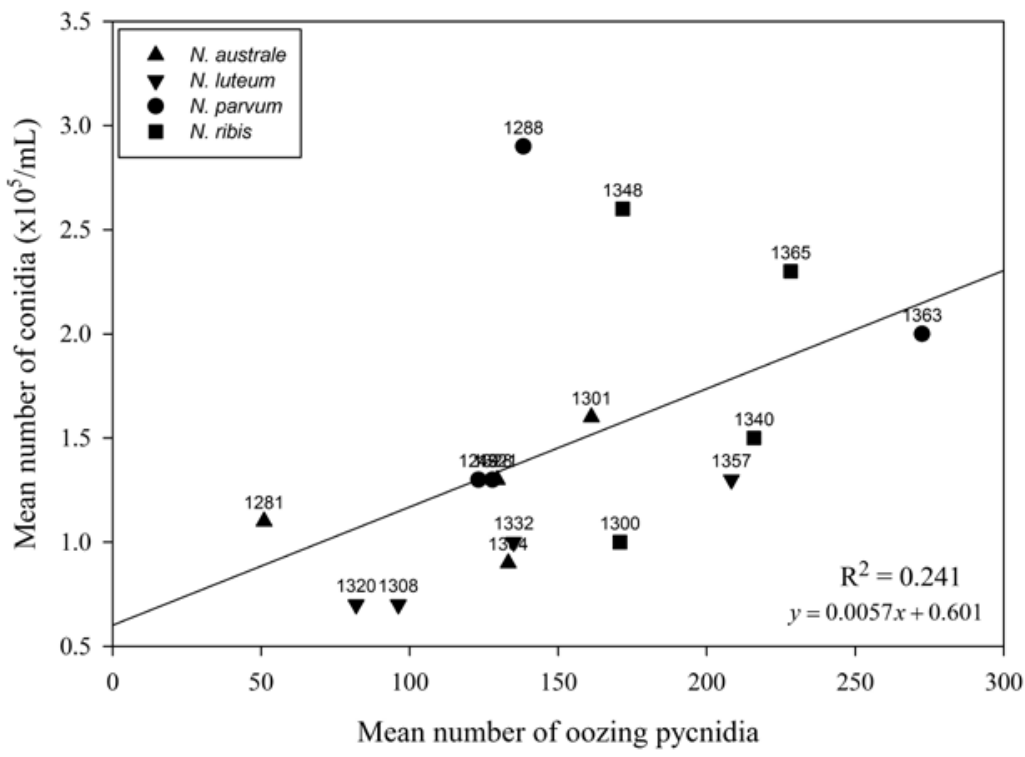

Figure $\quad 1 \quad$ Linear correlation between the mean number of oozing pycnidia and mean number of conidia $\left(\mathrm{x} 10^{5} /\right.$ $\mathrm{mL}$ ) of four isolates from each of four Neofusicoccum species, and the corresponding coefficient of determination $\left(\mathrm{R}^{2}\right)$ value. 
recovered from uninoculated control shoots. There was a significant effect of species $(\mathrm{P}<0.001)$ on the length of stem tissue colonised by the pathogen, with the mean colonisation length across both wounded and non-wounded shoots being significantly greater for $N$. ribis $(47.1 \mathrm{~mm})$ than $N$. australe $(30.4 \mathrm{~mm})$. There was a significant effect of wounding $(\mathrm{P}<0.001)$, with mean colonisation length being significantly greater for wounded shoots $(47.1 \mathrm{~mm})$ than non-wounded shoots $(30.4 \mathrm{~mm})$. There was a significant effect of tissue type $(\mathrm{P}=0.007)$ on colonisation length, with means of 44.2 and 33.3 $\mathrm{mm}$ respectively, for bark and wood. There were no significant interactions between species and wounding $(\mathrm{P}=0.057)$, species and tissue type $(\mathrm{P}=0.665)$, wounding and tissue type $(\mathrm{P}=0.388)$ and species, wounding and tissue type $(\mathrm{P}=0.828)$.

\section{DISCUSSION}

In the current study, pycnidia that oozed cirrhi of conidia were produced by all isolates of all four species with slightly higher numbers of both pycnidia and conidia produced by $N$. ribis followed by $N$. parvum, N. luteum and $N$. australe. Although significant differences were observed between species and isolates, the small differences in numbers of pycnidia and conidia produced by the different species may not translate into a meaningful difference with regard to disease epidemiology. The study will need to be repeated to determine whether the differences between species and isolates are real or the result of random variation, and further studies are required to determine whether such differences give certain isolates or species an advantage over others. The results of the current study however, were not consistent with the results of Amponsah et al. (2008) in grapevines, who tested three isolates each of $N$. australe, $N$. luteum, $N$. parvum, D. seriata and D. mutila. In that study, no conidia were produced by $N$. parvum isolates and the highest numbers of conidia were produced by $N$. luteum followed by $N$. australe isolates. However, no data on the variability between isolates were presented. In the current study, the number of oozing pycnidia and conidial numbers varied between isolate. Lesion size was not measured in the current study with the experimental tissue used to determine the sporulation potential being the central 15 $\mathrm{mm}$ of the lesion. However, for isolates that produced longer lesions in the initial shoots, this experimental tissue would potentially represent older more advanced lesioned tissue, which were more ready to sporulate compared with isolates that produced shorter lesions. Although this relationship has not been reported for Botryosphaeriaceae species on any of the host plants, studies with other diseases have shown such effects. Studies done on wheat (Triticum aestivum) cultivars infected by Septoria tritici (Eyal 1971) showed that the leaf necrosis area correlated with the number of pycnidia produced.

In this study, there was a positive correlation between the number of pycnidia produced on blueberry shoots and conidia released, which agrees with the findings reported by Amponsah et al. (2008) for Botryosphaeriaceae species on grapevine shoots. However, the numbers of conidia produced for some isolates, such as N. parvum LUPP1288 and N. ribis LUPP1348, was greater than expected based on the number of pycnidia which formed on the blueberry tissues. Similar results were obtained by Yang et al. (2017) where, of the two N. ribis and two $N$. parvum isolates tested, $N$. ribis isolate LUPP1348 was reported to produce the most conidia in the shortest time using an in vitro method involving interrupting mycelial mats produced on agar plates, with wet and dry cycles. In the current study, all oozing pycnidia were counted, although the amount of ooze varied greatly, as did the size and colour of the pycnidia. Pycnidia with more ooze may have released more conidia than those with less ooze. Not all pycnidia in the current study may have been sufficiently mature for optimum sporulation. Longer incubation could have increased maturity and spore production and should be considered when repeating this experiment.

In the pathogenicity assay, overall symptom development was higher in wounded than nonwounded tissues and higher for $N$. ribis than 
$N$. australe. In non-wounded shoots only $N$. ribis produced brown dots at the inoculation point which did not develop into clear lesions. Similar observations were reported by Milholland (1971) when attached wounded and non-wounded blueberry succulent stems were inoculated with Fusicoccum aesculi conidia. In the current experiment, isolations showed that the pathogens were able to latently infect nonwounded shoots, and progress endophytically in both wood and bark tissues, although there was a trend for the pathogen progression to be higher in wounded tissues than in non-wounded tissues. Further studies are needed to determine whether symptoms could develop from the latent endophytic growth, and the conditions under which this happens. However, since the results show that Neofusicoccum spp. are able to infect non-wounded tissue, any environmental conditions conducive to conidial production and release, irrespective of whether wounds are present, will represent risk periods for infection and should be considered when developing disease management strategies.

\section{ACKNOWLEGEMENTS}

We thank Lincoln University for funding this research.

\section{REFERENCES}

Amponsah NT, Jones EE, Ridgway HJ, Jaspers MV 2008. Production of Botryosphaeria species conidia using grapevine green shoots. New Zealand Plant Protection 61: 301-305.

Creswell TC, Milholland RD 1988. Spore release and infection periods of Botryosphaeria dothidea on blueberry in North Carolina. Plant Disease 72: 342-346.
Espinoza JG, Braceno EX, Chavez ER, UrbezTorres JR, Latorre BA 2009. Neofusicoccum spp. associated with stem canker and dieback of blueberry in Chile. Plant Disease 93(11): 1187-1194.

Eyal Z 1971. The kinetics of pycnospore liberation in measurements, and assuming infinitely thin pycnidium Septoria tritici. Canadian Journal of Botany 49: 1095-1099.

Milholland RD 1971. Histopathology and pathogenicity of Botryosphaeria dothidea on blueberry stems. Phytopathology 62: 654-660.

Tennakoon KMS 2017. Botryosphaeria disease in New Zealand blueberry gardens: identification of pathogens, inoculum sources and factors affecting disease development. Lincoln University, Lincoln, New Zealand, $\mathrm{PhD}$ thesis.

Tennakoon KM, Jaspers MV, Ridgway HJ, Jones EE 2015. Herbicide injuries on blueberry provide suitable infection sites for Neofusicoccum ribis. New Zealand Plant Protection 68: 411-414.

Wright AF, Harmon PF 2010. Identification of species in the Botryosphaeriaceae family causing stem blight on southern highbush blueberry in Florida. Plant Disease 94: 966-971.

Xu C, Zhang H, Zhou Z, Hu T, Wang S, Wang Y, Cao K 2015. Identification and distribution of Botryosphaeriaceae species associated with blueberry stem blight in China. European Journal of Plant Pathology 143(4): 737-752.

Yang YL, Turner J, Stephens J, Campbell RE, Walter M 2017. Comparison of in vitro and in planta sporogenesis in Neofusicoccum species from blueberry. New Zealand Plant Protection 70: 203-208. 